\title{
Zoological detective stories: the case of the facetotectan crustacean life cycle Gerhard Scholtz
}

Address: Humboldt-Universität zu Berlin, Institut für Biologie/Vergleichende Zoologie, Philippstrasse 13, 10115 Berlin, Germany. Email: gerhard.scholtz@rz.hu-berlin.de

Published: 26 June 2008

Journal of Biology 2008, 7:16 (doi:10.1 I86/jbiol77)

The electronic version of this article is the complete one and can be found online at http://jbiol.com/content/7/5/16

(c) 2008 BioMed Central Ltd

\begin{abstract}
The reconstruction of complete animal life cycles is sometimes a considerable problem, even though the knowledge of the full life cycle may have far-reaching evolutionary implications. A new study published in BMC Biology on artificially induced metamorphosis in an enigmatic crustacean group that was only known from larval stages sheds new light on the evolution of parasitism.
\end{abstract}

In our course on evolutionary biology, we ask the students to compare larvae, pupae, and imagines of the mealworm beetle Tenebrio molitor with the aim of finding direct evidence that these specimens represent not different species but the stages that every individual of this hexapod species has to pass through. The students cannot solve this problem. In spite of the most meticulous comparative morphological analysis there is no way to show that a larva and an adult beetle belong together. Even modern molecular markers reach their limits when only part of the life cycle is known and we have no clue where to look for the missing stages. Thus, the only method to resolve this issue is the direct observation of the life cycle, including metamorphosis and change of shape during ontogeny.

The early stages of a complex life cycle can have a morphology and an ecology that are dramatically different from those of the adults. Accordingly, the history of zoology, in particular during the 19th century, is full of dramatic 'detective stories'. An example is the detection by August Müller in 1856 [1] that the ammocoete is not a chordate species in its own right but the larval stage of the lamprey and thus a vertebrate. There was an even bigger sensation in
1866 when Alexander Kowalevsky [2] identified the larvae of tunicates and revealed that ascidians are chordates and not mollusks, and thus that these humble animals are kin to vertebrates, including humans. Similarly, in 1870 Elie Metschnikoff [3] showed that tornaria larvae do not belong to an unknown echinoderm group but are the larvae of hemichordate enteropneust worms with an adult morphology entirely different from that of sea urchins or sea stars.

These examples show that the results of these studies often had implications that helped to clarify phylogenetic relationships in metazoans and led to important evolutionary conclusions. For instance, the metamorphosis of ammocoete larvae to adult lampreys revealed that the thyroid gland derives from the endostyle of the chordate gill basket. Hence, Müller's and Kowalevsky's findings together paved the way for our current view that long ago the ancestor of humans was a sessile, filter-feeding animal. In a recent article published in BMC Biology, Henrik Glenner and colleagues [4] show that these kinds of investigations and evolutionary inferences are still a valid part of modern life sciences. They artificially induced metamorphosis in an enigmatic crustacean group that has been known for more 


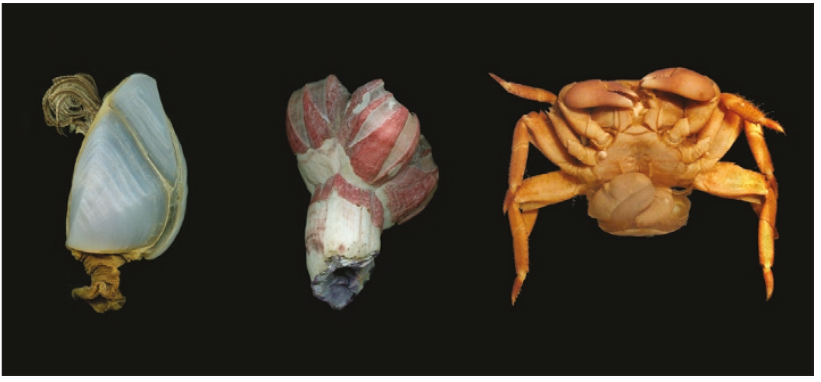

Figure I

Representatives of Cirripedia. From left to right: a goose barnacle (Thoracica, Lepadidae); an Indo-Pacific giant acorn barnacle (Thoracica, Balanidae); and the externa of a parasitic Sacculina (Rhizocephala) sitting under the abdomen of a crab.

than a hundred years exclusively by its larval stages. With this study, the authors approach the solution of one of the last major riddles of the complex biology of thecostracan crustaceans, which has puzzled numerous zoologists over the past two centuries.

The Thecostraca is a strange group of crustaceans that most non-zoologists would not identify as Crustacea at all. The adults are sessile filter feeders or parasites. The most visible subgroup of the Thecostraca is the Cirripedia, which includes the filter-feeding goose and acorn barnacles and the parasitic Rhizocephala (Figure 1). With their cirri and their often massive, calcified articulated shell, barnacles show a morphology and lifestyle that are very different from those of other crustaceans and of arthropods in general [5]. The parasitic forms are even more derived and sometimes hardly recognizable as animals. The differences from other crustaceans are also found at the molecular genetic level, where alterations in the Hox gene complex have been described [6]. On the basis of their appearance, early zoologists such as Conrad Gesner or Georges Cuvier $[7,8]$ associated barnacles with mollusks. This view is reflected in the German vernacular name Entenmuscheln (duck mussels). Because of their many derived features and problematic systematization, the Cirripedia have always attracted the interest of researchers, among them Johann Wolfgang von Goethe and Charles Darwin, the latter writing two large monographs on their biology.

Barnacles, and this is true for Cirripedia and their kin in general, are one of those groups whose phylogenetic position has only been resolved by the recognition of their life cycle. The details of cirripede ontogeny were for a long time entirely unknown, although some speculations existed, the most curious of which was that barnacles represented early ontogenetic stages of geese, probably the Brent Goose
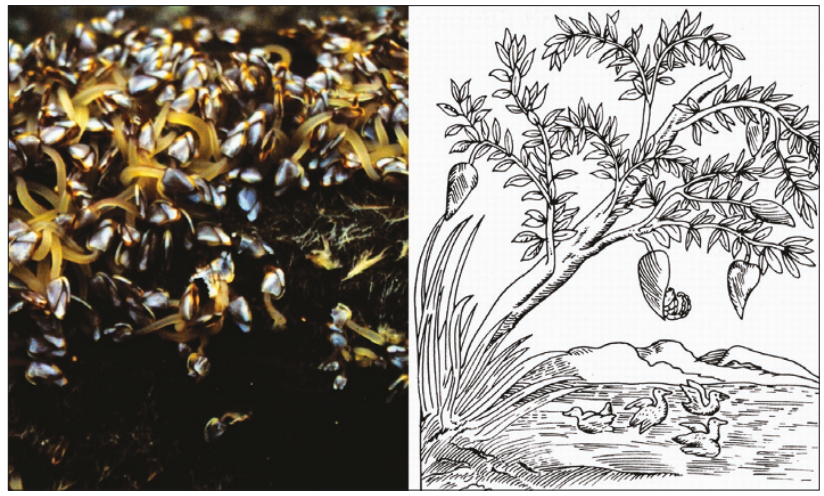

Figure 2

Barnacles as early stages in the life cycle of geese. Left: goose barnacles attached to a drifting log. Right: medieval view of the 'goose tree' producing geese of the genus Branta from barnacles.

Branta bernicla (Figure 2) [9]. This view was based on the shape and color of pedunculated barnacles such as Lepas, with the stalk corresponding to the neck and the cirri to the feathered tail of the geese and was held to explain the fact that wooden branches covered with barnacles are often found on the shore, while the geese are absent during summer. According to this idea, there were trees on northern islands that grow the barnacles as fruits on their branches. If they are ripe they metamorphose into geese, but sometimes branches with unripe specimens break off and are washed to European coasts. This had the practical implication that geese were considered as vegetarian food suitable for consumption during Lent or on Good Friday [10]. This story is reasonable in the sense that it puts a number of distinct observations in a logical context and illustrates the problem of inferences on life cycles based on independent bits of information. The idea of 'goosetrees' persisted long after the real mode of reproduction of Branta was known.

All hypotheses about relationships to mollusks or geese came to an end when John Vaughan Thompson [11] recognized that barnacles and their kin pass through the nauplius stage, which is the characteristic larval type of Crustacea [12]. Thus, Thompson's first achievement was the indisputable placement (as he himself stated in the title of his contribution) of barnacles among crustaceans. But he went even further. As noted above, the endoparasitic Rhizocephala show the most dramatic deviation of shape from other cirripedes. The adults form root-like networks inside the body cavities of their crustacean hosts (for example, the green crab Carcinus maenas), the so-called interna, and a sack on the outer surface of the host, the externa, containing the sexual organs and the embryos 
(Figure 1). Nobody would associate these strange animals with crustaceans, but again, Thompson showed that the larval stages reveal rhizocephalan affinities [13]. They pass through a nauplius stage, which already confirms that they are crustaceans, but more specifically, some naupliar characteristics, such as the frontolateral horns, unambiguously indicate that they belong to the cirripedes [14].

The occurrence of a more advanced larval stage, the cypris, with its characteristic morphology and behavior, strongly corroborates this relationship. As is the case in barnacles, the cypris of rhizocephalans is the stage at which the animal finds an appropriate place to settle and begin metamorphosis to the adult stage. For this purpose the cypris is originally equipped with compound eyes and with antennae that are capable of bipedal walking and possess glands producing adhesive glue [15]. The life cycle of some of these rhizocephalans has only recently been completely understood. One of the most unexpected and most interesting features is the occurrence of an infectious stage, the vermigon, which is injected by the late cypris into the host organism [16]. This vermigon is a more or less undifferentiated liquid-filled tube with a thin cuticle lacking any trace of segmentation and all internal organs. Apart from the epidermis and the chitinous cuticle, virtually nothing indicates an arthropod relationship.

However, this is not the end of the story of unresolved or resolved life cycles in cirripedes and their kin. With regards to one group among the Thecostraca, we are still at the 19th-century stage of knowledge. The Facetotecta or y-larvae were first described in the 1880s [16,17], but although they occur virtually worldwide and apparently in many species, only larvae, namely nauplii and cypris-like stages, have been found and never any adults. As in the cases described above, the specific characteristics of facetotectan nauplius and cypris larvae indicate their kinship to cirripedes. According to morphological and molecular evidence, Facetotecta are the sister group to the rest of the Thecostraca $[14,18]$ (Figure 3).

\section{Sensational solutions}

The work of Glenner et al. [4] provides a partial but sensational solution to the mystery of the enigmatic life cycle of Facetotecta. With simple but ingenious experiments they 'persuaded' facetotectan cypris larvae to undergo metamorphosis. The authors raised the larvae caught from plankton around Japan in Petri dishes up to the cypris, the latest stage known. To determine the species, they collected the exuviae of the molt of the last nauplius stage. They added defined doses of the molting hormone 20hydroxyecdysone (20-HE) and two other substances that initiate metamorphosis in Cirripedia to the cypris larvae of

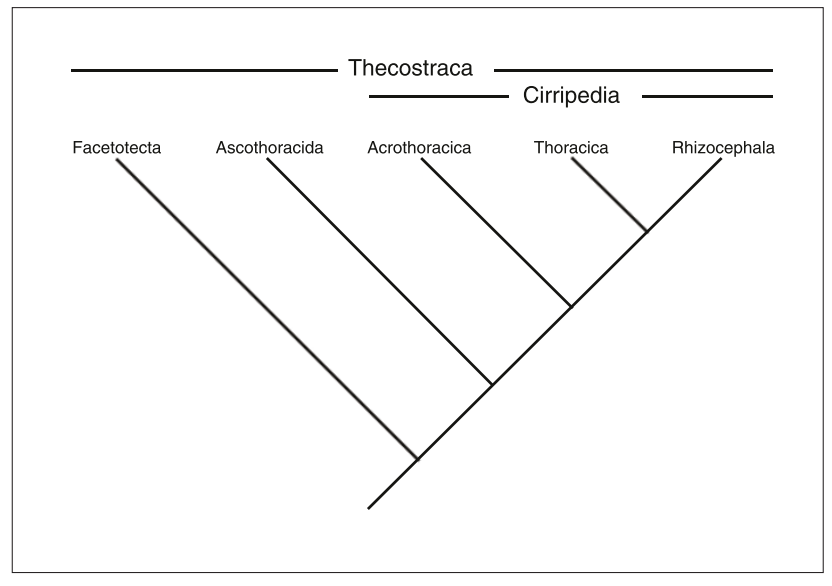

Figure 3

Phylogenetic relationships of Thecostraca (after $[14,18])$. Facetotecta is the sister-group to the rest of the Thecostraca, which comprise the Ascothoracida and Cirripedia. Despite their phylogenetic distance from Rhizocephala, the early postlarval stages (ypsigon) are very similar.

Facetotecta. However, only 20-HE caused metamorphosis of y-larvae. To the surprise of the authors, they produced a worm-like undifferentiated stage comparable to the rhizocephalan vermigon. Accordingly, the authors baptized this stage 'ypsigon', as a blend of vermigon and y-larvae.

This finding has several interesting implications. First of all, the occurrence of the ypsigon strongly suggests an endoparasitic lifestyle of the yet unknown adult Facetotecta. And this might explain why adults have never been detected so far. To find out more about adult facetotectans, the question is now which animal group forms the hosts? The widespread distribution of y-nauplii indicates a quite abundant host organism or group of organisms. If one considers a degree of host specificity similar to that in rhizocephalans, then it is very likely that there are a number of host species.

Another implication of the results of Glenner et al. [4] relates to the phenomenon of convergence. As mentioned above, it is quite obvious on the basis of morphological and molecular data that Facetotecta is the sister-group to the other Thecostraca and is thus not a subtaxon of Rhizocephala (Figure 3). From the pattern of lifestyles in its various subgroups it can be deduced that Thecostraca were originally not highly derived endoparasites. Nevertheless, different degrees of parasitism evolved independently in various lineages, and this is perhaps not so surprising, given that the starting point is a sessile lifestyle on various substrates, including other animals such as echinoderms, crustaceans and whales. The exciting new aspect of this discovery is the high degree of convergent similarity of the 
facetotectan ypsigon and the rhizocephalan vermigon. This raises again the question of what kind of adult parasitic form we should expect in Facetotecta - a structure similar to the root-like network of Rhizocephala? If this were the case, the surprising degree of convergence might be even higher. Glenner et al. have made a big step towards the complete description of the facetotectan life cycle but we are not there yet.

After an odyssey with presumed affinities to mollusks, plants, and geese and curious interpretations of their life cycles, the Thecostraca arrived safely in the crustaceans and most aspects of their partly bizarre life cycles have been resolved. With the present knowledge, it is obvious that the various aspects of thecostracan evolution offer very interesting insights into the origin of parasitism, the degree of alterations of body organizations within animals, and into questions related to homology and convergence of morphological structures. The study of Glenner and colleagues reveals that classical zoological investigations at the organismic level still have a lot to tell.

\section{References}

I. Müller A: Ueber die Entwickelung der Neunaugen. Ein vorläufiger Bericht. Arch Anat Phys Wissensch Med 1856:323-339.

2. Kowalevsky AO: Entwicklungsgeschichte der einfachen Ascidien. Mém Acad Sci St Petersburg 1866, 10:1-19.

3. Metschnikoff E: Untersuchungen über die Metamorphose einiger Seethiere. I. Ueber Tornaria. Z Wiss Zool 1870, 20: I 3I-I 44.

4. Glenner H, Høeg JT, Grygier MJ, Fujita Y: Induced metamorphosis in crustacean y-larvae: towards a solution to a 100-year-old riddle. BMC Biol 2008, 6:2I.

5. Anderson DT: Barnacles: Structure, Function, Development and Evolution. London: Chapman \& Hall; 1994.

6. Deutsch JS, Mouchel-Vielh E, Quéinnec É, Gibert J-M: Genes, segments, and tagmata in cirripedes. In Evolutionary Developmental Biology of Crustacea. Edited by Scholtz G. Lisse: Balkema; 2004:19-42.

7. Gesner C: Gesneri redivivi, aucti et emendati tomus IV. Et ultimus. Oder Vollkommenes FischBuch. Frankfurt am Main: Wilhelm Serlins; 1670.

8. Cuvier G: Le Régne Animal. Vol. II. Paris: Deterville; 1817.

9. Moray R: A relation concerning barnacles. Phil Trans $R$ Soc Lond 1677/1678 12:925-927.

10. Hulme FE: Myth-Land. London: Brampton; 1886.

II. Thompson JV: On the cirripedes or barnacles; demonstrating their deceptive character; the extraordinary metamorphosis they undergo, and the class of animals to which they undisputably belong. Zoological researches, and Illustrations; or Natural History of nondescript or imperfectly known animals. I830 I, I,IV:69-82.

12. Scholtz G: Evolution of the nauplius stage in malacostracan crustaceans. J Zool Syst Evol Res 2000 38: 175 - 187

13. Thompson JV: Natural history and metamorphosis of an anomalous crustaceous parasite of Carcinus maenas, the Sacculina carcini. Ent Mag Lond I836, 3:456.

14. Høeg JT, Lagersson NC, Glenner H: The complete cypris larva and its significance in thecostracan phylogeny. In Evolutionary Developmental Biology of Crustacea. Edited by Scholtz G. Lisse: Balkema; 2004:197-215.

15. Glenner H, Høeg JT: A new motile, multicellular stage involved in host invasion by parasitic barnacles (Rhizocephala). Nature 1995, 377:147-150.
16. Hensen V: Über die Bestimmung des Planktons oder des im Meer treibenden Materials an Pflanzen und Thieren. Bericht der Kommission zur wissenschaftlichen Untersuchung der deutschen Meere I887, 5: I-I08.

17. Hansen HJ: Die Cladoceren und Cirripedien der Plankton-Expedition. Ergeb Plankton-Expedit Humboldt-Stift I899, 2: I-58.

18. Perez-Losada M, Høeg JT, Kolbasov GA, Crandall KA: Reanalysis of the relationships among the Cirripedia and the Ascothoracida and the phylogenetic position of the Facetotecta (Maxillopoda: Thecostraca) using I8S rDNA sequences. J Crust Biol 2002, 22:66I-669. 